(c) 2017, THE AUTHORS. Published by FASS and Elsevier Inc. on behalf of the American Dairy Science Association ${ }^{\circledR}$.

This is an open access article under the CC BY-NC-ND license (http://creativecommons.org/licenses/by-nc-nd/3.0/).

\title{
Crystallization and demineralization phenomena in washed-rind cheese
}

\author{
Gil F. Tansman, ${ }^{*}$ Paul S. Kindstedt, ${ }^{*}$ and John M. Hughes $†$ \\ *Department of Nutrition and Food Sciences and \\ †Department of Geology, University of Vermont, Burlington 05405
}

\section{ABSTRACT}

This report documents an observational study of a high-moisture washed-rind cheese. Three batches of cheese were sampled on a weekly basis for $6 \mathrm{wk}$ and again at wk 10. Center, under-rind, rind, and smear samples were tested for $\mathrm{pH}$, moisture, and selected mineral elements. Powder x-ray diffractometry and petrographic microscopy were applied to identify and image the crystal phases. The $\mathrm{pH}$ of the rind increased by over $2 \mathrm{pH}$ units by wk 10 . The $\mathrm{pH}$ of the under-rind increased but remained below the rind $\mathrm{pH}$, whereas the center $\mathrm{pH}$ decreased for most of aging and only began to rise after wk 5. Diffractograms of smear material revealed the presence of 4 crystal phases: brushite, calcite, ikaite, and struvite. The phases nucleated in succession over the course of aging, with calcite and ikaite appearing around the same time. A very small amount of brushite appeared sporadically in center and underrind samples, but otherwise no other crystallization was observed beneath the rind. Micrographs revealed that crystals in the smear grew to over $250 \mu \mathrm{m}$ in length by wk 10, and at least 2 different crystal phases, probably ikaite and struvite, could be differentiated by their different optical properties. The surface crystallization was accompanied by a mineral diffusion phenomenon that resulted, on average, in a $217,95.7$, and $149 \%$ increase in calcium, phosphorus, and magnesium, respectively, in the rind by wk 10. The diffusion phenomenon caused calcium, phosphorus, and magnesium to decrease, on average, by $55.0,21.5$, and $36.3 \%$, respectively, in the center by wk 10. The present study represents the first observation of crystallization and demineralization phenomena in washed-rind cheese.

Key words: crystal, ikaite, demineralization, washedrind cheese

Received April 23, 2017.

Accepted August 2, 2017.

${ }^{1}$ Corresponding author: gtansman@uvm.edu

\section{INTRODUCTION}

Washed-rind cheese is a broad classification that includes cheeses of widely varying moisture content and aging time. The qualifying characteristic of washed rind cheeses is the treatment of the rind with a brine during aging, which can be applied by hand or with an implement such as a brush. Cheeses treated in this manner tend to form a complex microbiota on the surface that contributes to the appearance and flavor of the ripe cheese. The present observational study focuses on the development of a high-moisture washed-rind cheese that is characterized by a thick bacterial smear.

There exists a striking homology between the ripening of washed-rind cheese and the ripening of white mold (bloomy rind) cheese in that both types of cheese possess a highly active surface biomass that is carefully cultivated by the cheesemaker. In white mold cheese, the surface flora's activity causes a local increase in $\mathrm{pH}$ at the surface which causes $\mathrm{pH}$-sensitive calcium phosphate crystals to nucleate in the rind (Le Graet et al., 1983). The elevated $\mathrm{pH}$ reduces the solubility of calcium and phosphate in the rind and causes calcium and phosphate ions to diffuse to the rind from the center along a concentration gradient. These ions are deposited in growing crystals, which results in calcium phosphate accumulation in the rind and concurrent diminishment in the center. Elevated rind $\mathrm{pH}$ during aging has been reported in washed-rind cheese (Gobbetti et al., 1997), but corresponding investigation of crystallization and demineralization in washed-rind cheese appears to be absent from the literature.

Rind alkalinization in washed-rind cheese is a function of the various microbial communities that colonize the cheese surface and metabolize cheese components. At the initial $\mathrm{pH}$ of washed-rind cheese (typically between 5.0 and 5.5), the bacterial species that characterize the mature smear of washed-rind cheese cannot grow (Gori et al., 2007) and, instead, a succession of microbes colonizes the cheese surface as the collective microbial metabolism raises the $\mathrm{pH}$ (Mounier et al., 2006). The first species to appear are the yeasts, such as Debaryomyces hansenii (Riahi et al., 2007b), Kluyveromyces lactis, and Saccharomyces cerevisiae 
(Kagkli et al., 2006), that grow on account of their high acid and salt tolerance (Larpin et al., 2006). Yeast activities, including metabolism of lactic acid (Masoud and Jakobsen, 2005) and ammonia production (Gori et al., 2007), during early aging contribute to a significant increase in surface $\mathrm{pH}$. The acid sensitivity of successive bacterial colonies varies, but in general the bacterial species begin to grow around $\mathrm{pH} 6$ (Bockelmann and Hoppe-Seyler, 2001; Gori et al., 2007).

The main bacterial species that tend to appear on the cheese surface after the yeasts are gram-positive bacteria including Corynebacterium, Arthrobacter, Brevibacterium, Micrococcus, and Staphylococcus (Feurer et al., 2004). The process of washing the surface of the cheese with a brine has the effect of spreading the bacterial colonies over the rind and creating a uniform mass (Brennan et al., 2002). These bacteria form a sticky biofilm or microbial mat on the cheese surface (Leclercq-Perlat et al., 2004; Wolfe et al., 2014) that consists of the bacteria and excreted substances (Larpin et al., 2006). In contrast to the well-characterized microbial diversity, an analysis of the extracellular components of the smear appears to be absent from the literature. The bacterial smear communities continue to metabolize the cheese substrate, with further release of ammonia (Leclercq-Perlat et al., 2000b) and consumption of lactate (Leclercq-Perlat et al., 2000a).

The isolation and identification of crystals from the smears of 2 washed-rind cheeses was reported by the authors of the present manuscript (Tansman et al., 2017b). The crystals, which had never been observed in cheese, ranged in size with the largest crystals measuring several hundred microns in length. One of the isolated crystals was identified as ikaite $\left(\mathrm{CaCO}_{3} \cdot 6 \mathrm{H}_{2} \mathrm{O}\right)$, which is a rare metastable crystal that is mostly associated with freezing marine and lacustrine environments. The other crystal was struvite $\left(\mathrm{NH}_{4} \mathrm{MgPO}_{4} \cdot 6 \mathrm{H}_{2} \mathrm{O}\right)$, which is often associated with bacterial activity.

The primary goal of the present study was to observe the nucleation and growth of crystals in a washedrind cheese during aging and to measure the changes in mineral element concentrations at different depths of the cheese. Novel crystallographic techniques were employed to observe the maximum size of crystals and to identify the crystal phases at different points during aging.

\section{MATERIALS AND METHODS}

\section{Cheese Manufacture}

Cheeses were obtained from The Cellars at Jasper Hill (Greensboro, VT; herein referred to as The Cellars). The cheese variety observed in the present study corresponded to cheese A in the authors' previous publication (Tansman et al., 2017b) and is commercially marketed as Winnimere. The general recipe for this variety is as follows: cheeses are manufactured from nonstandardized raw cow milk produced at Jasper Hill Farm during the winter months using a washed-rind procedure approximately similar to that described by Sozzi and Shepherd (1972). The milk is inoculated with cultures that are proprietary and therefore the specific cultures are not included in this description. The curds are dipped at $\mathrm{pH} 6.55$ and drained in molds measuring $14 \mathrm{~cm}$ in diameter. The curds drain at room temperature until the $\mathrm{pH}$ reaches approximately 6.0 , at which point they are transferred to a refrigerated chamber at approximately $2^{\circ} \mathrm{C}$ and drained overnight. The wheels are demolded at a $\mathrm{pH}$ of approximately 5.45 and dry salted to a target salt-in-moisture of approximately $2.6 \%$. This salt content is relatively low, but is within the range reported by Mounier et al. (2005) for other varieties of washed-rind cheese. Target cheese moisture content at demolding is approximately $55 \%$, although considerable drainage continues during the first few days. The cheese is aged in a 13 to $14^{\circ} \mathrm{C}$ (94 to $95 \%$ humidity) room for the first week, after which it is transferred to a 10 to $11^{\circ} \mathrm{C}(96 \%$ humidity) aging vault. Immediately before being placed in the aging vault, the cheeses are wrapped with a strip of spruce bark around the outer diameter of the cheese, which is fastened with a rubber band. The cheese is scrubbed with a mediumlength-bristle brush dipped in brine 3 times in the first week and then twice per week until the fourth week. From demolding, the cheese is aged on wire racks for a total of $6 \mathrm{wk}$ and then wrapped in semi-permeable paper and stored at $4.5^{\circ} \mathrm{C}$ until shipment. At the time of wrapping, each wheel weighs approximately $570 \mathrm{~g}$. The cheese described by Sozzi and Shepherd (1972) is considered ripe at $20 \mathrm{~d}$, but due to the regulatory environment, the cheese in the present study is aged at a lower temperature and for a longer time before packaging and distribution.

\section{Cheese Sampling}

Cheeses were sampled at wk $1,2,3,4,5,6$, and 10 , on the same day of the week. The wk- 1 samples were delivered $2 \mathrm{~d}$ after demolding, which dictated the day of the week that the subsequent samples were collected. The cheeses were wrapped in cheese paper and delivered by overnight post to the Department of Nutrition and Food Sciences at the University of Vermont in insulated coolers with ice packs. Two wheels were collected from The Cellars at wk 1, 2, 3, 4, and 5. Four wheels were collected at wk 6 , which was the last week of cave-aging and the first week of packaging and cold storage. Two 
of the wheels collected at wk 6 were used for analysis upon arrival and the 2 additional wheels were stored in an incubator at $4.5^{\circ} \mathrm{C}$ until wk 10 , thereby simulating the storage conditions used in the manufacturing facility. The entire experiment was replicated 3 times using 3 different batches of cheese produced 1 wk apart on the same day of the week.

\section{Cheese Sectioning for Data Collection}

The cheeses were precisely segmented with a wire cutter to remove an approximately $8.5 \mathrm{~cm}$ by $3 \mathrm{~cm}$ (length $x$ width) section along the diameter of the cheese, which included a portion of the outer diameter (including a piece of the spruce bark) and the approximate center of the cheese (Figure 1). Serial sections measuring roughly $1.5 \mathrm{~cm}$ were cut from the part of the excised portion that represented the approximate center of the wheel. Rind, under-rind, center, and smear samples were collected from the serial sections as follows: a 2-mm-thick sample that included the smear and underlying cheese for the rind; a 2-mm-thick sample underneath the rind sample for the under-rind; a 2-mm-thick sample from the center of the cheese for the center; and a scraping of the surface biomass from the opposite face of the cheese from which the rind sample was taken for the smear. Smear samples were collected by gently scraping the cheese surface using a metal spatula. A harvestable smear biomass did not manifest until wk 3 in any of the batches; therefore, smear measurements were not available for any of the variables during the first 2 wk.
Cheese samples were partitioned as described above for all analyses including powder x-ray diffractometry (PXRD), microscopy, elemental analysis, and moisture content analysis. For $\mathrm{pH}$, the rind measurements were collected from the rind surface, the under-rind measurements were collected $2 \mathrm{~mm}$ below the surface, and the center measurements were collected at the approximate center of the cheese. It should be noted that the $\mathrm{pH}$ sampling scheme involved only 3 measurement locations, in contrast to the other measurements, in which 4 different sampling locations were used. Samples for PXRD, pH, and microscopy were partitioned from the cheeses on the same day that the cheeses arrived from The Cellars, or on the day that they were removed from incubator (at wk 10). The remnants of each cheese were carefully vacuum packaged and frozen at $-20^{\circ} \mathrm{C}$. Elemental analysis and moisture analysis were conducted on the previously frozen samples at a later date using the same cheese sampling plan described above.

\section{pH Measurements}

The $\mathrm{pH}$ measurements were conducted using a flat $\mathrm{pH}$ electrode (Thermo Fisher Scientific, Waltham, MA). Readings were allowed to stabilize for $1 \mathrm{~min}$ before recording.

\section{Petrographic Microscopy}

Small quantities of collected material from the various sampling locations were applied to glass microscope

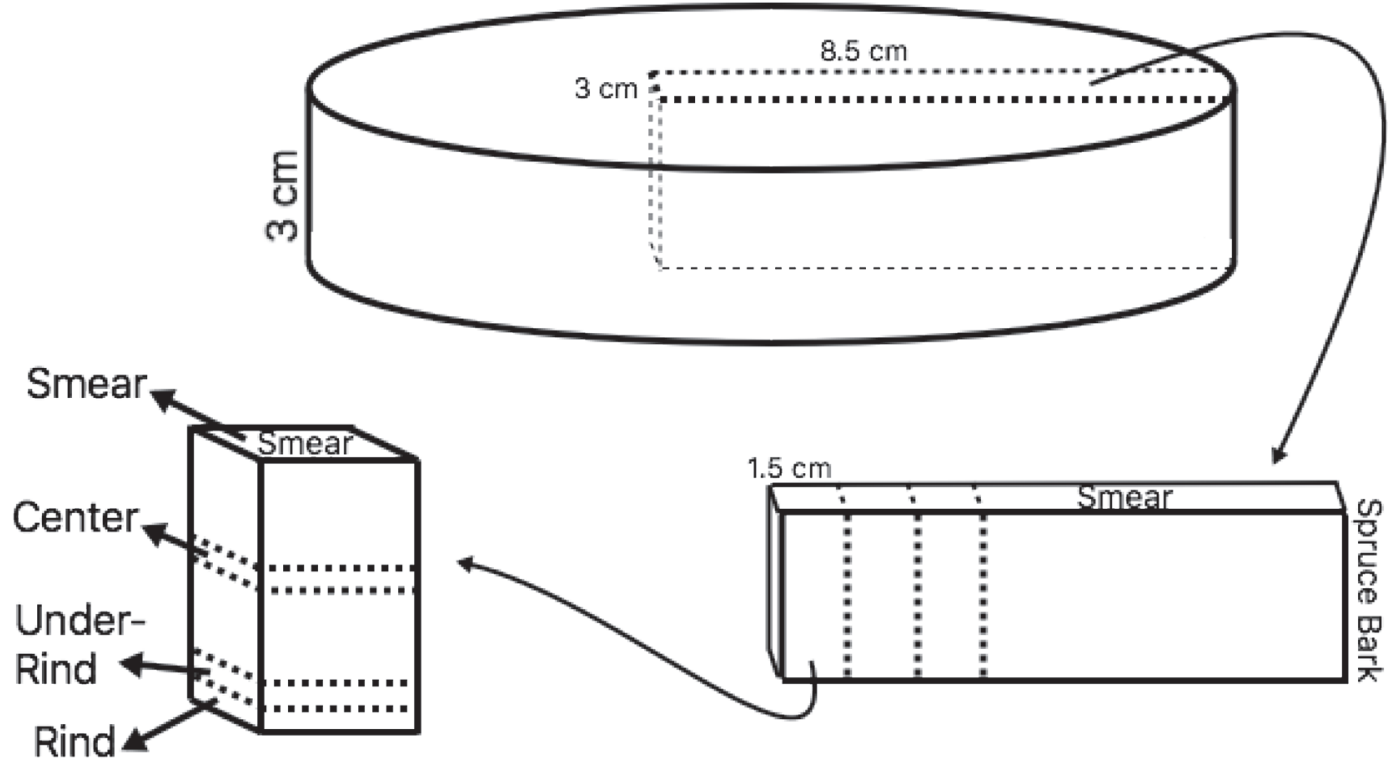

Figure 1. Illustration of the sampling scheme used for sectioning cheese into smear, rind, under-rind, and center samples. 
slides and gently pressed to translucent thinness using a glass coverslip with care taken to avoid crushing any crystals. Micrographs were captured using a Nikon E200POL petrographic microscope with a rotating stage (Nikon Corporation, Tokyo, Japan) and a SPOT Idea 1.3 Mp color camera (SPOT Imaging Solutions, Sterling Heights, MI). When the polarizers were crossed, particles that were illuminated and displayed uniform extinction were identified as crystals.

\section{PXRD}

Aliquots of cheese from each sampling location were homogenized with a mortar and pestle and loaded onto glass diffraction slides. Data were collected on a MiniFlex II powder x-ray diffractometer (Rigaku, The Woodlands, TX). To minimize diffraction artifacts that tend to occur when smear samples dry during data collection, a small quantity of mineral oil was added to the surface smear samples to limit the sample drying. Mineral oil was not applied to rind, under-rind, and center samples because these did not tend to dehydrate as quickly as the smear material. Diffractograms were generated at a speed of $2^{\circ} 2 \theta / \mathrm{min}$ between 5 and $50^{\circ} 2 \theta$. Diffractograms were compared with existing diffraction reference cards archived in the International Centre for Diffraction Data (ICDD) database.

\section{Elemental Analysis}

Samples were digested following EPA Method SW846-3015, "Microwave Assisted Acid Digestion of Aqueous Samples and Extracts" (EPA, 2007). Approximately $0.25 \mathrm{~g}$ of homogenized sample from each sampling location were placed in a Teflon reaction chamber, weighed to $0.001 \mathrm{~g}$, and $10 \mathrm{~mL}$ of concentrated nitric acid was added. The chambers were sealed and placed in the microwave system (CEM MARS-5, Matthews, $\mathrm{NC}$ ), which gradually increased the samples to $190^{\circ} \mathrm{C}$ over $15 \mathrm{~min}$, and then held them at $190^{\circ} \mathrm{C}$ for $15 \mathrm{~min}$. After cooling, the digested samples were transferred quantitatively to $50-\mathrm{mL}$ volumetric flasks and brought to volume with $0.1 \mathrm{~N}$ nitric acid.

The digests were analyzed for calcium, magnesium, and phosphorus by inductively coupled plasma-optical emission spectrometry (Optima 3000DV, Perkin Elmer Corp., Norwalk, CT) on a dual-view instrument operating in axial view with an radio frequency power of 1,300 W. Calibration standards were prepared according to instrument manufacturer's suggested guidelines to cover the range of concentrations in the sample set. Two-point calibrations (plus a calibration blank) were used for inductively coupled plasma analysis. Continuing calibration verification samples, prepared from an independent source, were used to check the calibration periodically. Concentrations of minerals were calculated on a cheese dry weight basis using the corresponding moisture data collected for each sample.

\section{Moisture Analysis}

The collected material from each sampling location was homogenized with a mortar and pestle. Approximately $1 \mathrm{~g}$ of homogenized material from each sampling location was weighted into a preweighed aluminum drying dish and then placed in a draft oven at $100^{\circ} \mathrm{C}$ for $24 \mathrm{~h}$, which was found to dry the samples to a constant weight. These values were used to calculate moisture content and to convert corresponding elemental data to a dry weight basis.

\section{Statistical Analysis}

The experiment was conducted as a 3-factor randomized block design with batches representing blocks and 7 sampling points per batch. Two one-way analyses of variance were conducted using data for $\mathrm{pH}$, selected mineral elements on a dry weight basis, and moisture content using the statistical package JMP Pro 12.0.0 (SAS Institute Inc., Cary, NC). The first ANOVA was conducted using data that started at wk 3 (5 time points) due to the absence of smear data for the first 2 wk (Table 1). The absence of smear data from the first 2 wk made it impossible to calculate interactive effects for the first $2 \mathrm{wk}$, and therefore introduced singularity errors into the statistical analysis. A second ANOVA was conducted, which omitted the smear treatment but included all time points. These 2 analyses were compared to determine if there were any differences in the significance of main or interaction affects between the models. It should be noted that regardless of the ANOVA used, the $\mathrm{pH}$ variable had only $2 \mathrm{df}$ because only 3 sampling locations (rind, under-rind, and center) were used in $\mathrm{pH}$ measurements.

\section{RESULTS}

\section{Moisture, $p H$, and Elemental Analyses}

All main and interactive effects for the mineral elements on a dry weight basis and $\mathrm{pH}$ were significant (Table 1). Sampling location and the interaction between sampling location and week were significant for moisture content, but week was not significant. It should be noted that in the ANOVA that contained all 7 time points but omitted the smear treatment (data not shown), all main and interactive effects, including week, were significant for all variables, which may re- 
Table 1. Mean squares, probabilities (in parentheses), and $\mathrm{df}$ for $\mathrm{pH}$, selected mineral elements on a dry weight basis, and moisture content starting on wk 3 ( 5 time points)

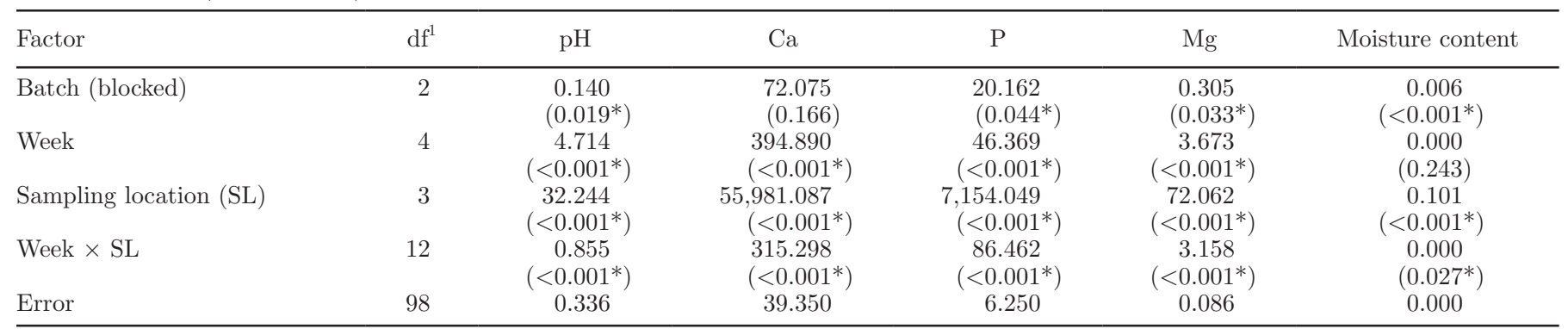

${ }^{1}$ Degrees of freedom for $\mathrm{pH}$ are 2 (blocked), 4 (week), 2 (SL), 8 (week $\times \mathrm{SL}$ ), and 73 (error).

*Statistical significance $(P<0.05)$ is denoted by an asterisk.

flect the significantly lower moisture readings for center samples in the first $2 \mathrm{wk}$ (Figure 2) that were omitted in the initial ANOVA.

The mean $\mathrm{pH}$ was initially between 5.3 and 5.5 throughout the cheese and decreased by 0.1 to $0.2 \mathrm{pH}$ units by wk 2 . The $\mathrm{pH}$ at the center continued to decline with further ripening, whereas it rose on the outside after wk 2, especially at the rind surface (Figure $3)$. The $\mathrm{pH}$ of the rind increased almost $1.5 \mathrm{pH}$ units between wh 2 and 3 , whereas the $\mathrm{pH}$ of the under-rind did not increase to that extent until after wk 6 . The $\mathrm{pH}$ of the rind continued to rise through wk 6 and decreased slightly thereafter. After wk 6 , the $\mathrm{pH}$ of the center, which had decreased by almost $0.4 \mathrm{pH}$ units during early aging, also rose appreciably, although it remained lower than the under-rind.

The increase in smear $\mathrm{pH}$ was accompanied by a large increase in the concentrations of calcium (Figure

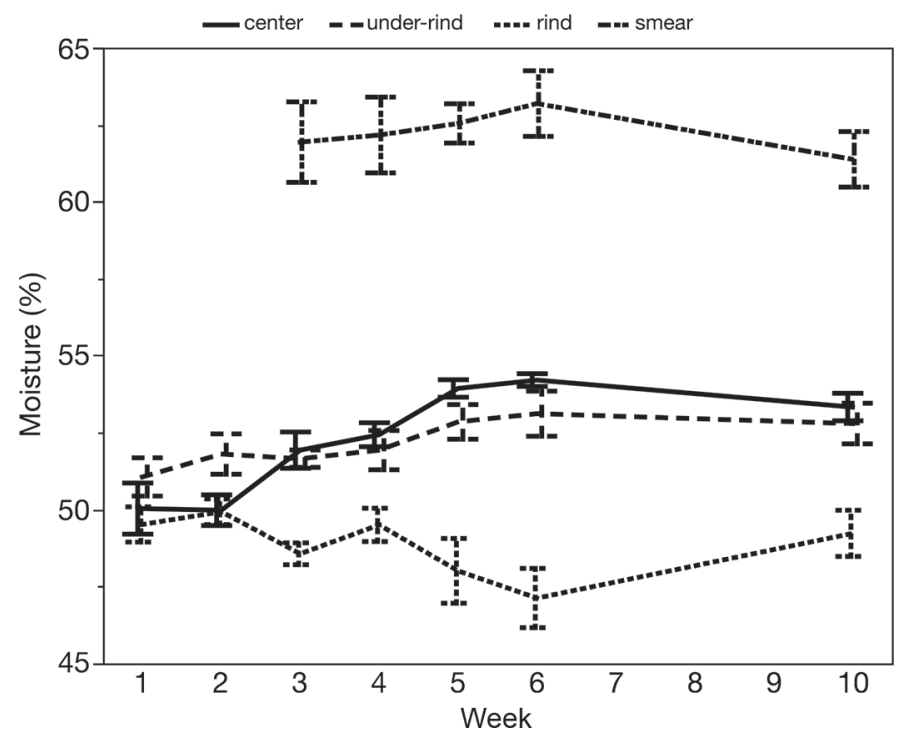

Figure 2. Mean moisture content of cheese during aging; error bars $=\mathrm{SE}$.
4), phosphorus (Figure 5), and magnesium (Figure 6) in the rind. After exhibiting limited change during the first $2 \mathrm{wk}$, the increased concentrations in the rind appeared almost linear between wk 2 and 6 . The magnesium concentration in the rind continued to rise linearly through wk 10, whereas the rind calcium concentration increased at a slower rate, and the rind phosphorus concentration did not increase after wk 6 . Over the 10 wk of aging, concentrations of the 3 elements in the under-rind and the center decreased almost linearly. The concentrations of calcium, phosphorus, and magnesium in the under-rind and the center were similar throughout aging. Concentrations of the 3 elements in the smear, which was sampled starting on wk 3, were consistently several times greater than corresponding element concentrations in the other sampling locations at any given time point.

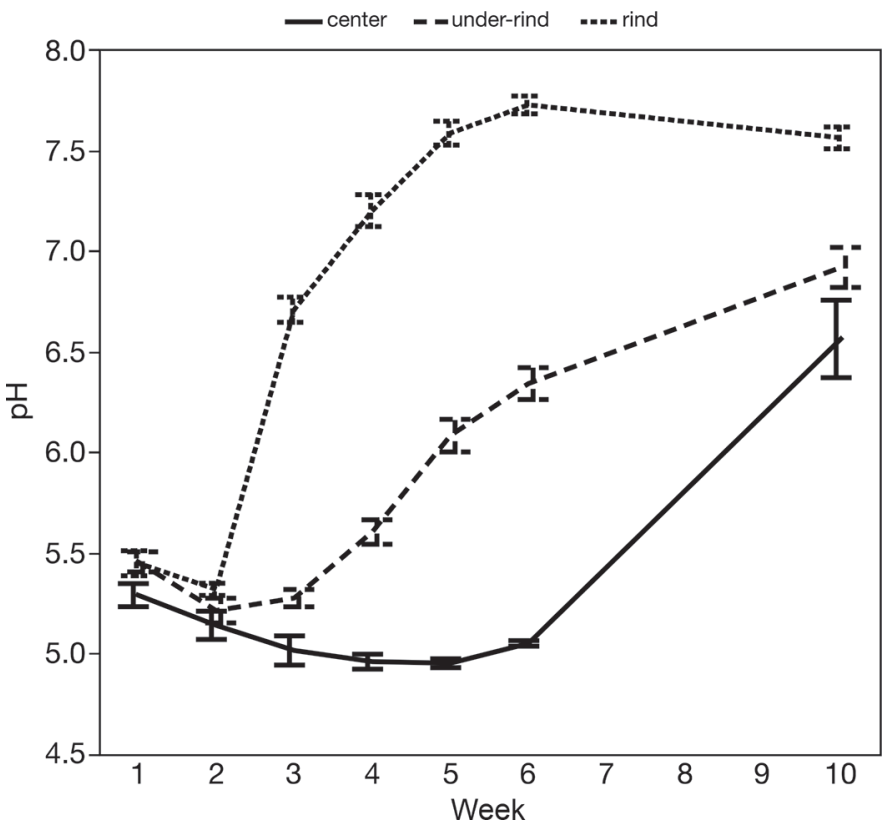

Figure 3. Mean $\mathrm{pH}$ of cheese during aging; error bars = SE. 


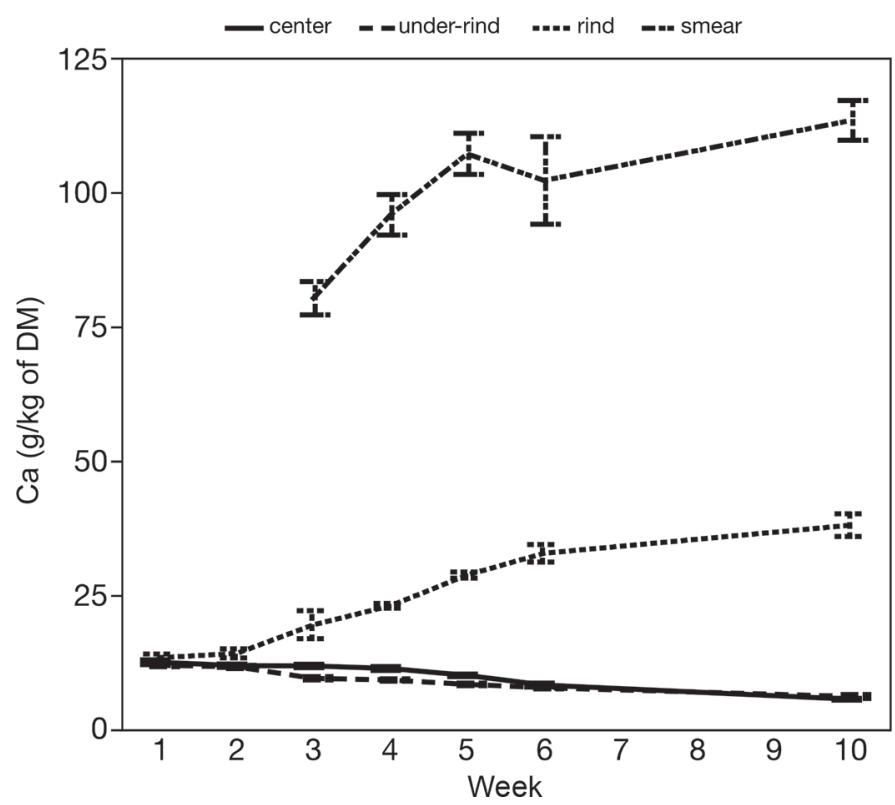

Figure 4. Mean calcium content $(\mathrm{g} / \mathrm{kg}$ of $\mathrm{DM})$ of cheese during aging; error bars $=\mathrm{SE}$.

Moisture content changed very little during aging (Figure 2). A slight increase was observed at center and under-rind locations between wk 1 and 6 , whereas the moisture content of the rind decreased during the same time. Between wk 6 and 10, the moisture content of the rind recovered to wk 1 levels, whereas the moisture content of the center slightly decreased. The moisture

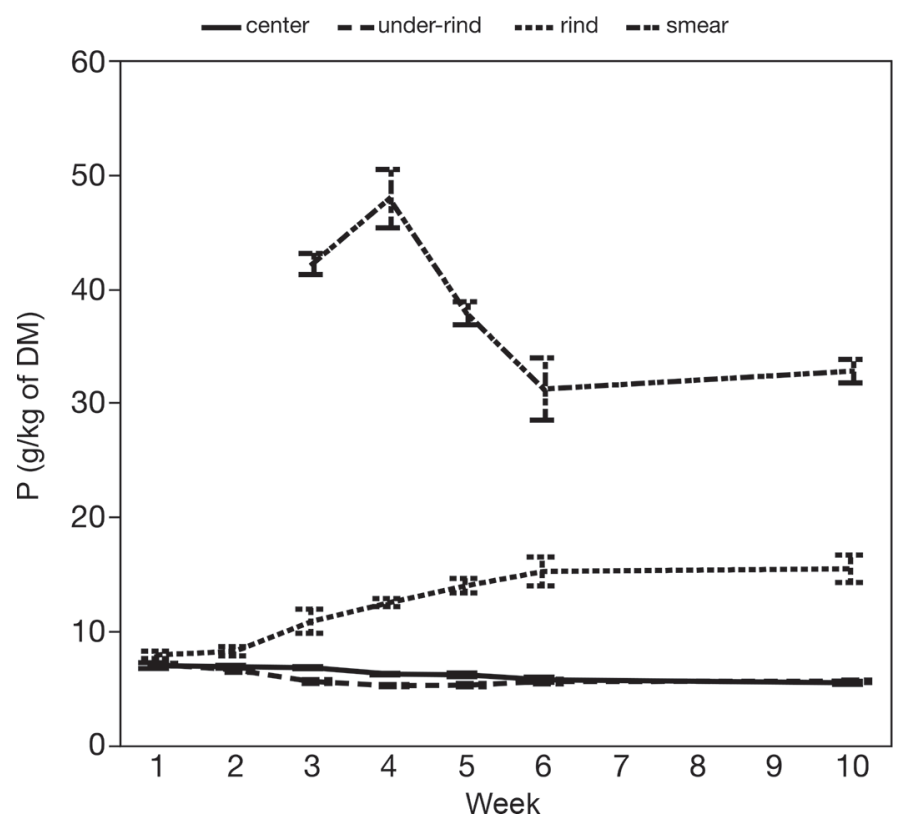

Figure 5. Mean phosphorus content ( $\mathrm{g} / \mathrm{kg}$ of $\mathrm{DM}$ ) of cheese during aging; error bars $=\mathrm{SE}$.

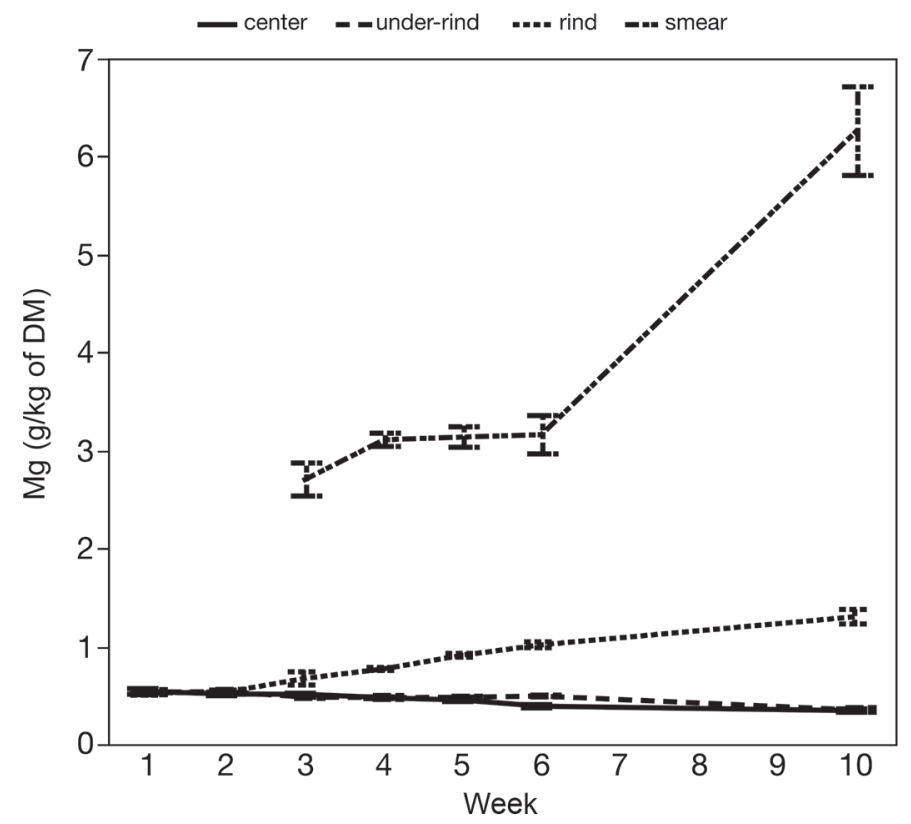

Figure 6. Mean magnesium content ( $\mathrm{g} / \mathrm{kg}$ of $\mathrm{DM})$ of cheese during aging; error bars $=\mathrm{SE}$.

content of the smear, which was consistently higher than the other sampling locations by 10 to $15 \%$, peaked at wk 6 , and then returned to the wk 3 level by wk 10 .

\section{PXRD}

Small diffraction peaks that appeared in rind diffractograms by wk 2 grew in intensity and were identifiable as brushite $\left(\mathrm{CaHPO}_{4} \cdot 2 \mathrm{H}_{2} \mathrm{O}\right)$ in rind and smear samples by wk 3 (data not shown). Smear diffractograms, which were generally superior in quality to rind diffractograms, provided a better record of crystal activity on the surface after smear material manifested at wk 3 (Table 2). Some smear diffractograms exhibited preferred orientation, a commonly encountered diffraction artifact, wherein the intensities of the diffraction peaks are distorted such that some peaks are larger and others are smaller compared with the ideal diffraction pattern. This results from nonrandom orientation of crystals within the sample, which occurs if the crystals are not fully ground or if they fracture into crystallites with distinctly elongated planes, such as needles or plates. This artifact was much less pronounced in wk 6 and 10 smear diffractograms, and it is not clear why younger smears were more prone to this artifact. The absence or diminished intensity of some or all major diffraction peaks due to preferred orientation made conclusive identification of crystal phases in younger smears difficult and contributed to some of the observed variability in phase identification. 
Table 2. Crystal phases identified by powder x-ray diffractometry in smear samples over 10 wk of aging ${ }^{1}$

\begin{tabular}{lclllll}
\hline Batch & Replicate & 3 wk & 4 wk & 5 wk & 6 wk & 10 wk \\
\hline 1 & 1 & Brushite & Brushite calcite & Calcite ikaite & Calcite ikaite & Calcite ikaite struvite \\
1 & 2 & Brushite & Calcite & Calcite ikaite & Calcite ikaite & Calcite ikaite struvite \\
2 & 1 & Brushite & Brushite & Calcite ikaite & Calcite ikaite & Calcite ikaite struvite \\
2 & 2 & Brushite & Brushite & Calcite ikaite & Calcite ikaite struvite \\
3 & 1 & Brushite calcite & Brushite & Calcite ikaite & Calcite ikaite & Calcite ikaite struvite \\
3 & 2 & Brushite calcite & Brushite & Calcite ikaite & Calcite ikaite struvite \\
\hline
\end{tabular}

${ }^{1}$ Smear data were collected starting at wk 3. Italicized crystal names indicate tentative identification.

Brushite was conclusively identified in most smear diffractograms starting at wk 3, which was the first time point at which collectable smear material appeared on the cheese surface. At wk 4, the intensity of brushite peaks in smear diffractograms increased, but by wk 5 brushite had disappeared from all smear diffractograms. In contrast, brushite persisted in rind diffractograms for the duration of the experiment (data not shown), indicating that after wk 5 brushite was present in the underlying cheese but not in the smear. Brushite was occasionally observed in under-rind and center diffractograms, although the peaks, if present, were always very small (data not shown), indicating that the quantity of brushite in those samples was noteworthy but limited.

Calcite $\left(\mathrm{CaCO}_{3}\right.$, ICDD card \#00-005-0586) was observed sporadically in wk 3 and 4 smear diffractograms (Table 2), and was observed in all smear diffractograms starting at wk 5. Calcite was somewhat difficult to conclusively identify because the only large peak, which is at $29^{\circ} 2 \theta$, coincides with a brushite peak at almost the same angle. Therefore, conclusive identification of calcite was only possible if brushite peaks were relatively small or absent. Conclusive identification of calcite was possible in all smear diffractograms starting at wk 5 and could be clearly identified in wk-10 diffractograms (Figure 7A).

Ikaite was identified or tentatively identified in most smear diffractograms by wk 5 (Table 2). Preferred orientation artifacts appeared to affect ikaite much more than other phases and appeared to be much more common in younger smear samples. These artifacts made conclusive identification of ikaite in wk 5 and in some wk-6 samples difficult, although conclusive identification of ikaite in all wk-10 diffractograms was straightforward (Figure 7B).

Struvite was observed in an all smear diffractograms at wk 10 (Table 2). The struvite peaks were small compared with the ikaite peaks, possibly indicating that less struvite was present (Figure 7C); however, semiquantitative comparison between different crystal phases is complicated by crystal chemistry, which also affects the intensity of diffraction peaks.

\section{Petrographic Microscopy}

Small pinpoint crystals measuring up to $10 \mu \mathrm{m}$ in diameter could be seen in all wk-4 smear samples (Figure 8A). These crystals corresponded to diffractograms containing brushite peaks. Crystals measuring up to approximately $200 \mu \mathrm{m}$ appeared at wk 5 (Figure 8B) and tended to be larger and more abundant at wk 6 (Figure $8 \mathrm{C}$ ). Week 5 and 6 diffractograms showed evidence of both calcite and ikaite crystals, which made it difficult to identify the larger crystals that formed at that time; however, the crystals displayed optical properties that were similar to crystals identified as ikaite in a previous study (Tansman et al., 2017b).

By wk 10, in addition to the large and abundant crystals that were tentatively identified as ikaite, a second type of crystal, differentiable by its colorful hue, was observed in all smear samples (Figure 8D). In a previous study, crystals with high birefringence resembling these colorful crystals were identified as struvite (Tansman et al., 2017b), and their manifestation in the present study coincided with the appearance of struvite in smear diffractograms. To conclusively determine if any of the large crystals at wk 10 were calcite, several wk-10 smears were allowed to dehydrate on the glass microscope slide and were reexamined. All of the large crystals on the slides dehydrated and lost their optical properties, which is a behavior characteristic of ikaite and struvite, but not attributable to calcite. Thus, although calcite was present in smear diffractograms at wk 10, it does not appear to have grown as large as ikaite and struvite crystals.

\section{DISCUSSION}

\section{Moisture Development During Aging}

Moisture loss is a complex process that is affected by factors such as the humidity in the aging chamber, air flow, and curd characteristics. The pattern of moisture development (Figure 2) was somewhat reminiscent of the moisture pattern observed by the authors of this manuscript in a recent study dealing with stabilized 


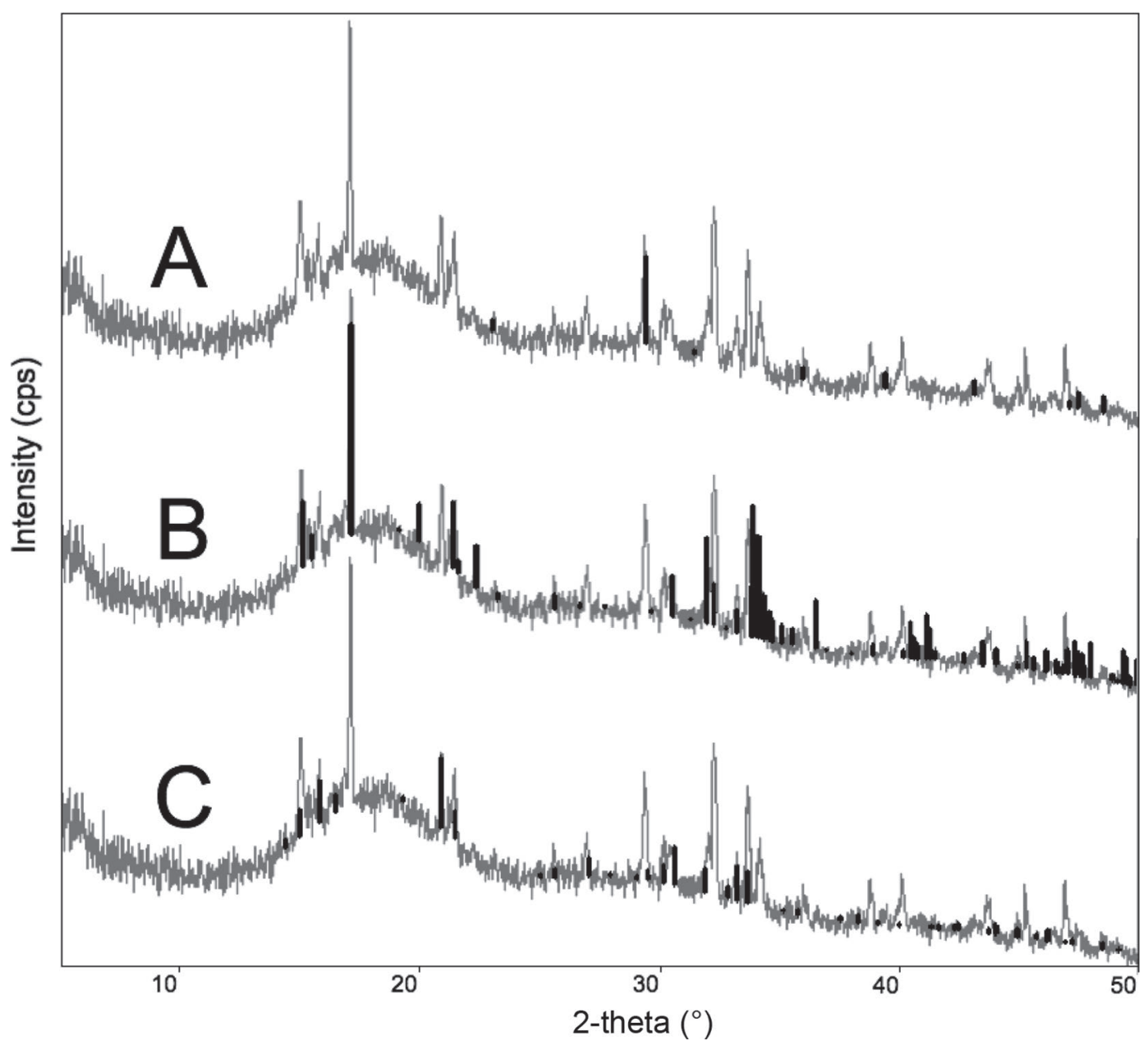

Figure 7. Powder x-ray diffractogram from a wk-10 smear sample with corresponding reference patterns for calcite [A, International Centre for Diffraction Data (ICDD) card \#00-005-0586], ikaite (B, ICDD card \#01-072-0670), and struvite (C, ICDD card \#00-015-0762). The y-axis shows arbitrary units of counts per second (cps).

white mold cheese (Tansman et al., 2017a). Although the small increase in moisture content at the center was a novel finding in the context of stabilized white mold cheese, there appears to be a greater precedent in washed-rind cheese. Other studies on washed-rind cheeses, aged under similar humidity and temperature, showed that the moisture content did not decrease during aging (O'Farrell et al., 2002; Riahi et al., 2007a). Notably, a study dealing with Vacherin (Sozzi and Shepherd, 1972), which is very similar to the cheese in the present study, appeared to show that the moisture content at the center of cheese from 2 different factories increased compared with the moisture content at the beginning of aging, whereas the rind moisture content decreased. Further investigation is needed to verify whether the moisture observations in the present study were artifacts of data collection.

\section{Accumulation of Mineral Elements in the Rind and Smear}

By wk 10, the average calcium, phosphorus, and magnesium content of the rind increased by $217,95.7$, and $149 \%$, respectively. The increase in mineral element content in the rind began after wk 2 (Figures 4, 5 , and 6), and coincided with a large increase in surface $\mathrm{pH}$ (Figure 3). Evidence of brushite crystallization was apparent in diffractograms of wk 3 rind samples and thus appeared to be the most likely destination for calcium and phosphorus accumulating in the rind. The initial accumulation of mineral elements in the rind at wk 3 also coincided with the first harvestable surface biomass. The smear biomass that manifested at wk 3 was fairly limited but already contained 3 to 4 times the concentration of mineral elements (on a dry weight 


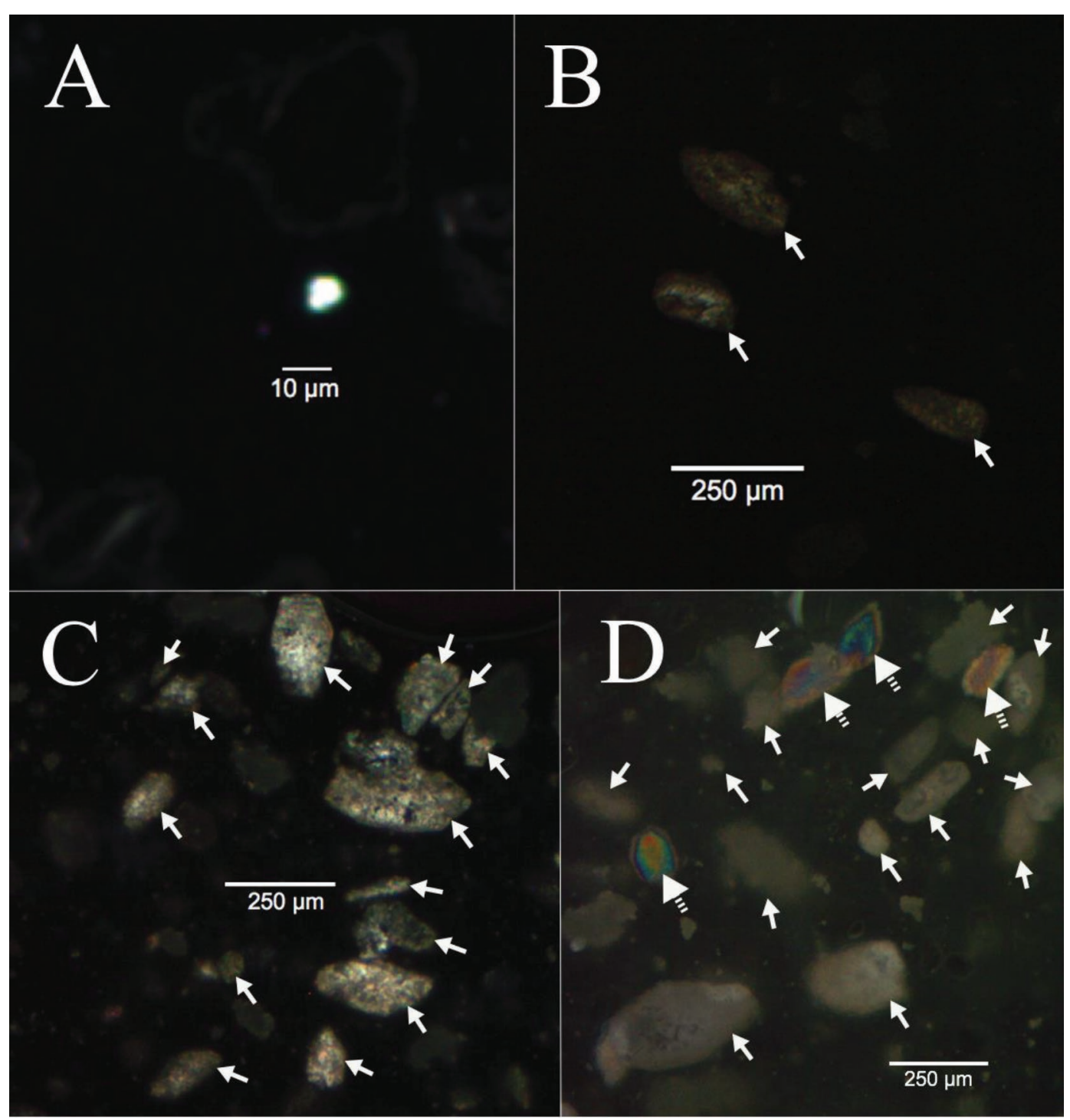

Figure 8. Petrographic micrograph series of smear samples at wk 4 (A), wk 5 (B), wk 6 (C), and wk 10 (D). Solitary crystal in A tentatively identified as brushite. Arrows in B through D indicate probable ikaite (small solid arrow) and struvite (large dashed arrow). Color version available online.

basis) as the composite rind (Figures 4,5 , and 6), suggesting that brushite crystallization was concentrated in the smear, although this cannot be conclusively determined from the data.

Calcium, phosphorus, and magnesium concentrations in the smear followed complex functions (Figures 4, 5, and 6) that sharply contrast with the nearly linear increase in mineral elements in the composite rind, which may reflect the fact that as crystals were nucleating in the smear, additional smear material was also accumulating. The sampling method in the present study could not be used to quantify the accumulation of smear biomass, but it became progressively easier to collect large quantities of smear as aging progressed, which suggested that the amount of biomass increased as aging progressed.

On a molar basis, calcium and phosphorus in the smear increased at a similar rate between wk 3 and 4 (data not shown), which may reflect the growth of brushite in the smear. From wk 4 to 5 phosphorus accumulation lagged behind calcium, which may reflect the disappearance of brushite and the growth of calcite and ikaite, both of which contain calcium but not phosphorus. Although brushite tends to become increasingly insoluble as the $\mathrm{pH}$ is increased, its insolubility tapers around neutrality (Johnsson and Nancollas, 1992). In contrast, the solubility of carbonates, including calcite, continues to decrease by several degrees of magnitude 
as the $\mathrm{pH}$ shifts from slightly acid to slightly alkaline (Giannimaras and Koutsoukos, 1987). Although the brushite in the smear appears to have completely dissolved by wk 5 , the concentration of phosphorus in the smear remained high compared with the rest of the cheese (Figure 5), even before struvite precipitation was evident. At wk 6, the concentration of phosphorus was still nearly double the concentration of phosphorus in the composite rind, suggesting that the diffusion of phosphorus into and out of the smear is a complex process.

The concentration of magnesium in the rind and smear was higher than in the center and under-rind by wk 3 (Figure 6) even though the magnesian phase struvite was not observed by PXRD before wk 10 (Table 2). Magnesium and calcium are both alkaline earth metals, and both brushite (Lee and Kumta, 2010) and calcite (Kunitake et al., 2012) can accommodate magnesium in calcium bonding sites. A small amount of atomic substitution in brushite and calcite could thus potentially explain the increased level of magnesium in the rind and smear before the appearance of struvite. However, diffractograms of minimally substituted phases cannot be easily differentiated from pure phases using PXRD, and the crystallographic data in the present study cannot confirm this assumption. The greatest accumulation of magnesium, however, was almost certainly due to the formation of struvite by wk 10, which was accompanied by a large increase in the concentration of magnesium in the smear between wk 6 and 10 (Figure 6).

\section{Extent of Demineralization}

The initial mineral element content of the cheese in the present study (Figures 4, 5, and 6) was higher than the mineral element content of traditional white mold and stabilized white mold cheeses used in other studies (Le Graet et al., 1983, Tansman et al., 2017a), and this likely reflects the higher $\mathrm{pH}$ profile during the manufacture of the cheese in the present study. A comparison of mean mineral element contents in the center at wk 1 and 10 revealed that over the experiment's duration mean calcium content decreased by $55.0 \%$, mean phosphorus content decreased by $21.5 \%$, and mean magnesium content decreased by $36.3 \%$. The proportion of crystal phases in the smear could not be quantified in this study, but the greater decrease in calcium content could reflect the fact that ikaite and calcite nucleated several weeks before struvite and therefore could have resulted in more extensive diffusion of calcium from the center to the rind.

An under-rind sampling location was examined to determine if there was a difference in mineral element content between the center of the cheese and the under- rind. Although there were slightly lower concentrations of each mineral element in the under-rind than the center at various points during aging, the concentration of each mineral element in the center and under-rind converged by the end of the study.

\section{Significance of Calcite, Ikaite, and Struvite}

Carbon dioxide and ammonia concentrations were not measured in the present study, but the manifestation of calcite, ikaite, and struvite, which contain these gases as components of their lattices, indicates that sufficient carbon dioxide and ammonia accumulated in the cheese to induce the precipitation of these minerals. These gases result from the metabolism of cheese components by cheese microorganisms (Riahi et al., 2007a). The observations in the present study suggest that surface crystallization is a result of both rind alkalinization, which affects mineral solubility, as well carbonate and ammonia accumulation, which provides the ions necessary for calcite, ikaite, and struvite formation.

The observation that ikaite crystallized in the presence of calcite is interesting because both phases contain calcium and carbonate groups and would thus compete for the same ions. The coexistence of both of these phases in the smear by the end of aging is also interesting because previous research has shown that ikaite is metastable and tends to transform into calcite (Marland, 1975). The ability of both ikaite and calcite to persist is noteworthy and warrants additional investigation.

\section{CONCLUSIONS}

The processes of rind alkalinization, surface crystallization, and cheese demineralization that had been previously observed in white mold cheese were documented for the first time in washed-rind cheese. A progression of nucleation events that resulted in brushite crystallization and subsequent dissolution, as well as calcite, ikaite, and struvite precipitation, was observed in the smear and represents the first observation of these 4 crystal phases in the same cheese. These observations open new opportunities for exploring crystallization phenomena in cheese. Additional research is necessary to understand the effect that these crystals have on rind grittiness in washed-rind cheese.

\section{ACKNOWLEDGMENTS}

This study was funded by USDA Hatch Project VTH02102. The National Science Foundation is gratefully acknowledged for support of grant EAR-0922961 for the purchase of the powder x-ray diffractometer and 
through support of grant NSF-MRI 1039436 for the purchase of the single crystal x-ray diffractometer. The Cellars at Jasper Hill (Greensboro, VT) is also gratefully acknowledged for providing the cheeses used in this study.

\section{REFERENCES}

Bockelmann, W., and T. Hoppe-Seyler. 2001. The surface flora of bacterial smear-ripened cheeses from cow's and goat's milk. Int. Dairy J. 11:307-314.

Brennan, N. M., A. C. Ward, T. P. Beresford, P. F. Fox, M. Goodfellow, and T. M. Cogan. 2002. Biodiversity of the bacterial flora on the surface of a smear cheese. Appl. Environ. Microbiol. 68:820830.

EPA. 2007. Method 3015A: Microwave Assisted Acid Digestion of Aqueous Samples and Extracts. SW-846 Compendium.

Feurer, C., T. Vallaeys, G. Corrieu, and F. Irlinger. 2004. Does smearing inoculum reflect the bacterial composition of the smear at the end of the ripening of a French soft, red-smear cheese? J. Dairy Sci. 87:3189-3197.

Giannimaras, E. K., and P. G. Koutsoukos. 1987. The crystallization of calcite in the presence of orthophosphate. J. Colloid Interface Sci. 116:423-430.

Gobbetti, M., S. Lowney, E. Smacchi, B. Battistotti, P. Damiani, and P. F. Fox. 1997. Microbiology and biochemistry of Taleggio cheese during ripening. Int. Dairy J. 7:509-517.

Gori, K., H. D. Mortensen, N. Arneborg, and L. Jespersen. 2007. Ammonia production and its possible role as a mediator of communication for Debaryomyces hansenii and other cheese-relevant yeast species. J. Dairy Sci. 90:5032-5041.

Johnsson, M. S. A., and G. H. Nancollas. 1992. The role of brushite and octacalcium phosphate in apatite formation. Crit. Rev. Oral Biol. Med. 3:61-82.

Kagkli, D., R. Tache, T. M. Cogan, C. Hill, S. Casaregola, and P. Bonnarme. 2006. Kluyveromyces lactis and Saccharomyces cerevisiae, two potent deacidifying and volatile-sulphur-aroma-producing microorganisms of the cheese ecosystem. Appl. Microbiol. Biotechnol. 73:434-442.

Kunitake, M. E., S. P. Baker, and L. A. Estroff. 2012. The effect of magnesium substitution on the hardness of synthetic and biogenic calcite. MRS Commun. 2:113-116.

Larpin, S., C. Mondoloni, S. Goerges, J. Vernoux, M. Gueguen, and N. Desmasures. 2006. Geotrichum candidum dominates in yeast population dynamics in Livarot, a French red-smear cheese. FEMS Yeast Res. 6:1243-1253.

Le Graet, Y., A. Lepienne, G. Brule, and P. Ducruet. 1983. Migration du calcium et des phosphates inorganiques dans les fromages à pâte molle de type Camembert au cours de l'affinage. Lait 63:317-332.

Leclercq-Perlat, M. N., G. Corrieu, and H. E. Spinnler. 2004. The color of Brevibacterium linens depends on the yeast used for cheese deacidification. J. Dairy Sci. 87:1536-1544.
Leclercq-Perlat, M. N., A. Oumer, J. L. Bergere, H. E. Spinnler, and G. Corrieu. 2000a. Behavior of Brevibacterium linens and Debaryomyces hansenii as ripening flora in controlled production of smear soft cheese from reconstituted milk: Growth and substrate consumption. J. Dairy Sci. 83:1665-1673.

Leclercq-Perlat, M. N., A. Oumer, F. Buono, J. L. Bergere, H. E. Spinnler, and G. Corrieu. 2000b. Behavior of Brevibacterium linens and Debaryomyces hansenii as ripening flora in controlled production of soft smear cheese from reconstituted milk: Protein degradation. J. Dairy Sci. 83:1674-1683.

Lee, D., and P. N. Kumta. 2010. Chemical synthesis and stabilization of magnesium substituted brushite. Mater. Sci. Eng. C 30:934-943.

Marland, G. 1975. The stability of $\mathrm{CaCO}_{3} 6 \mathrm{H}_{2} \mathrm{O}$ (ikaite). Geochim. Cosmochim. Acta 39:83-91.

Masoud, W., and M. Jakobsen. 2005. The combined effects of $\mathrm{pH}$, $\mathrm{NaCl}$, and temperature on growth of cheese ripening cultures of Debaryomyces hansenii and coryneform bacteria. Int. Dairy J. 15:69-77.

Mounier, J., R. Gelsomino, S. Goerges, M. Vancanneyt, K. Vandemeulebroache, B. Hoste, S. Scherer, J. Swings, G. F. Fitzgerald, and T. M. Cogan. 2005. Surface microflora of four smear-ripened cheeses. Appl. Environ. Microbiol. 71:6489-6500.

Mounier, J., S. Goerges, R. Gelsomino, M. Vaacanneyt, K. Vandemeulebroecke, B. Hoste, N. M. Brennan, S. Scherer, J. Swings, G. F. Fitzgerald, and T. M. Cogan. 2006. Sources of the adventitious microflora of a smear-ripened cheese. J. Appl. Microbiol. 101:668-681.

O'Farrell, I. P., J. J. Sheehan, M. G. Wilkinson, D. Harrington, and A. L. Kelly. 2002. Influence of addition of plasmin or mastitic milk to cheesemilk on quality of smear-ripened cheese. Lait 82:305-316.

Riahi, H., I. C. Trelea, M. N. Leclercq-Perlat, D. Picque, and G. Corrieu. 2007a. Model for changes in weight and dry matter during the ripening of a smear soft cheese under controlled temperature and relative humidity. Int. Dairy J. 17:946-953.

Riahi, M. H., I. C. Trelea, D. Picque, M. N. Leclercq-Perlat, A. Helias, and G. Corrieu. 2007b. A model describing Debaryomyces hanseni growth and substrate consumption during a smear soft cheese deacidification and ripening. J. Dairy Sci. 90:2525-2537.

Sozzi, T., and D. Shepherd. 1972. Evolution de la composition chimique et de la flore microbienne du fromage de Vacherin au cours de la maturation. Lait 52:203-219.

Tansman, G., P. S. Kindstedt, and J. M. Hughes. 2017a. Crystallization and demineralization phenomena in stabilized white mold cheese. J. Dairy Sci. 100:6074-6083.

Tansman, G.. P. S. Kindstedt, and J. M. Hughes. 2017b. Minerals in food: Crystal structures of ikaite and struvite from bacterial smears on washed-rind cheese. Can. Mineral. 55:89-100. https:// doi.org/10.3749/canmin.1600038.

Wolfe, B. E., J. E. Button, M. Santarelli, and R. J. Dutton. 2014 Cheese rind communities provide tractable systems for in situ and in vitro studies of microbial diversity. Cell 158:422-433. 